\title{
1 \\ Beyond the Stockholm Convention: An Introduction to Current Issues and Future Challenges in POPs Research
}

\author{
Stuart Harrad \\ Division of Environmental Health and Risk Management, School of Geography, \\ Earth, and Environmental Sciences, University of Birmingham, UK
}

The international significance of research into the sources, behaviour, fate, and effects of persistent organic pollutants (POPs) is exemplified by the Stockholm Convention for which the host organisation is the United Nations Environment Programme (UNEP). Following extensive negotiation, it was adopted on 22 May 2001, entered into force 90 days after the 50th party had ratified it on 17 May 2004, and by late 2008 there were over 180 participants (http://chm.pops.int/). The objective of the Convention is 'to protect human health and the environment from persistent organic pollutants' Among other things, it recognises the need for global action in recognition of the facts that POPs are toxic, resistant to degradation, and bioaccumulative. Furthermore, they are capable of global transport via air, water, and migratory species, and are deposited far from their place of release, where they accumulate in terrestrial and aquatic ecosystems.

As of 2008, there are 12 chemicals (or groups of chemicals) that are listed under the Convention. These 12 are listed in Table 1.1. The Convention also allows for the inclusion of additional chemicals under its scope. Parties to the Convention may propose such additions, and the case for their inclusion is considered by the POPs Review

Persistent Organic Pollutants Edited by Stuart Harrad

(C) 2010 Blackwell Publishing Ltd 
Table 1.1 Chemicals currently listed and under consideration for listing as POPS under the Stockholm Convention

\begin{tabular}{|c|c|}
\hline Currently listed & Under consideration \\
\hline Aldrin & Chlordecone $^{a}$ \\
\hline Chlordane & Endosulfan \\
\hline DDT & Hexabromobiphenyl $^{a}$ \\
\hline Dieldrin & Hexabromocyclododecane \\
\hline Endrin & $\alpha$-Hexachlorocyclohexane \\
\hline Heptachlor & $\beta$-Hexachlorocyclohexane \\
\hline Hexachlorobenzene & $\gamma$-Hexachlorocyclohexane (Lindane) ${ }^{a}$ \\
\hline Mirex & Octabromodiphenyl ether \\
\hline Polychlorinated biphenyls & Pentabromodiphenyl ether ${ }^{a}$ \\
\hline Polychlorinated dibenzo- $p$-dioxins & Pentachlorobenzene \\
\hline Polychlorinated dibenzofurans & Perfluorooctane sulfonate $^{a}$ \\
\hline Toxaphene & Short chain chlorinated paraffins \\
\hline
\end{tabular}

${ }^{a}$ Already recommended by the POPs Review Committee (POPRC) for listing under the Convention.

Committee (POPRC). For a chemical to be included in the Convention, it must display the following:

Persistence,

Bioaccumulation,

Potential for long-range environmental transport, and

Adverse effects.

Full details of the evidence required for these criteria to be fulfilled are included under Annex A of the text of the Stockholm Convention. As of late 2008, a further 12 chemicals were under consideration by POPRC for inclusion under the Convention. These are also listed in Table 1.1.

Inspection of Table 1.1 reveals that while all those listed under the original test of the Convention are organochlorines, those under consideration for inclusion include one organofluorine and a number of organobromine chemicals. Hence while this book addresses, to at least some degree, most or all of the chemicals listed in Table 1.1, it focuses particularly on polychlorinated biphenyls (PCBs), hexabromocyclododecane (HBCD), perfluorinated chemicals (PFCs), and polybrominated diphenyl ethers (PBDEs). These are selected on the basis that they either:

(a) represent an example of a currently listed POP that, despite significant efforts, remains of concern (i.e. PCBs), or

(b) are under consideration by POPRC and have been the subject of an explosion in scientific interest in the last decade (HBCD, PFCs, and PBDEs).

Both HBCD and PBDEs are examples of brominated flame retardants (BFRs). The recent growth in the number of scientific papers addressing the environmental presence and impacts of such chemicals has been quite phenomenonal. In a similar vein, there has been a dramatic rise in concerns related to the environmental presence and impacts of perfluorinated chemicals (PFCs). Chapters 2 and 3 thus address current knowledge and research 
priorities related to these groups of contaminants - often referred to as 'new' or 'emerging' POPs.

Making progress with understanding the environmental processes and pathways by which POPs transfer from their sources into wildlife and humans requires the application of sophisticated measurement techniques. One such area that has seen particular recent growth is the exploitation of the chiral properties possessed by several POPs. Chapter 4 describes how recent research in this field has provided new insights into the environmental sources and cycling of POPs.

Given the global nature of the Convention, it recognises that the nature of the problems faced by developing countries, and their capacity to tackle these problems, are often distinct from those associated with the developed world. For example, while in regions such as North America and western Europe concerns are expressed about human exposure arising from indoor contamination with BFRs emitted from items like consumer electronics, developing world concerns about BFRs are more likely to be related to issues such as emissions arising from the uncontrolled dumping and burning of BFR-containing waste, often shipped from the developed world (Athanasiadou et al., 2008). The vast majority of what is known about POPs concerns the developed world, despite evidence that substantial problems exist in developing countries. It is for this reason that Chapter 5 of this book addresses the situation regarding POP contamination in such regions.

The primarily agricultural applications of some organochlorine pesticides, combined with the bioaccumulative potential and persistence of POPs that confers their wellcharacterised capacity to accumulate in food chains, can lead to a perception that the problems associated with POPs are largely to be found in rural, food-producing regions. In reality the urban environment plays a pivotal role in driving the emissions of POPs. Coupled with the ever-increasing rate of urbanisation, the specific physical characteristics of our cities are also of interest as they interact with POPs in a very different fashion to rural regions. Chapter 6 therefore examines urban issues related to POPs.

Traditionally, because measurements of human exposure to POPs via the diet exceeded considerably that received via inhalation of outdoor air and ingestion of water, human exposure via pathways other than diet have in the past been largely ignored. Recently, however, researchers have realised that in instances where POPs have found appreciable indoor applications, the resultant elevated indoor contamination, coupled with the high proportion of time spent indoors (typically $90 \%$ or more in many countries) renders pathways of exposure other than diet of importance. In particular, the past widespread deployment of PCBs in, for example, building sealants has led to concentrations in indoor air that considerably exceed those present outdoors, to the extent that inhalation of such air is an appreciable exposure pathway (Currado and Harrad, 1998). More recently, attention has been drawn to the potential of incidental ingestion of indoor dust as a vector for exposure to brominated flame retardants and perfluorinated stain-proofing chemicals that enter dust as a result of their widespread deployment in electronic goods and fabrics, etc. (Abdallah, Harrad, and Covaci, 2008; Jones-Otazo et al., 2005; Shoeib et al., 2005). This is of special concern for infants and toddlers owing to their lower body weights and likely high dust ingestion rates compared to adults. Chapter 7 therefore examines the state of knowledge regarding the sources, levels, and human exposure implications of indoor contamination with POPs. 
Finally, there is a perception that banning manufacture and new use of a POP will suffice as a control measure. While such action will have a short-term beneficial impact, further reductions in contamination are likely to be limited for as long as goods and materials produced before the ban remain in use or are otherwise not destroyed. Where the 'turnover' or replacement time of such items is long, they will represent an ongoing emission source for some time after implementation of the ban on manufacture. One example is the existence of substantial stockpiles of unused organochlorine pesticides in developing countries. Another scenario more pertinent to the developed world is the burden of POPs associated with goods and materials contained within the built environment. In both such instances, the remaining burden of these chemicals requires urgent action if their release into the environment is to be prevented. The final chapter of this book describes how indoor contamination can migrate outdoors, enter the food chain and thus 'buffer' dietary exposure. Potentially more serious, however, is the potential for environmental contamination and concomitant human exposure that exists if emissions arising from the end-of-life disposal of POPs-treated goods and materials are incorrectly managed. Chapter 8 thus calls for a radical reevaluation of the way in which we manage the life cycle of goods and materials treated with POPs, so that environmental contamination at the end of their life is minimized.

In the four years since the Stockholm Convention came into force, there has been substantial progress in our understanding of the environmental sources, behaviour, and impacts of POPs. At the same time, new issues and challenges have emerged - not least the identification of 'new' POPs like BFRs and PFCs - alongside the development of new thinking and strategies to tackle the problems. This book is intended to go some way towards identifying and describing these. In the author's view, POPs are likely to continue to provide extremely fertile research ground for the foreseeable future. Given the number of new chemicals under consideration for listing under the Stockholm Convention - a trend that is unlikely to abate anytime soon - it is imperative that scientists and policy-makers learn as much as possible from current knowledge related to the sources, fate, behaviour, and effects of those POPs listed currently and which have already been the subject of study for several decades. Such action is essential to prevent us repeating the mistakes of the past.

\section{References}

Abdallah, M. A., Harrad, S., Covaci, A. (2008) Hexabromocyclododecanes and tetrabromobisphenol$\mathrm{A}$ in indoor air and dust in Birmingham, UK: implications for human exposure. Environ. Sci. Technol., 42: 6855-6861.

Athanasiadou, M., Cuadra, S. N., Marsh, G., Bergman, Å., Jakobsson, K. (2008) Polybrominated diphenyl ethers (PBDEs) and bioaccumulative hydroxylated PBDE metabolites in young humans from Managua, Nicaragua. Environ. Health Perspect., 116: 400-408.

Currado, G. M., Harrad, S. (1998) A comparison of polychlorinated biphenyl concentrations in indoor and outdoor air and the potential significance of inhalation as a human exposure pathway. Environ. Sci. Technol., 32: 3043-3047.

Jones-Otazo, H. A., Clarke, J. P., Diamond, M. L., Archbold, J. A., Ferguson, G., Harner, T., Richardson, G. M., Ryan, J. J., Wilford, B. (2005) Is house dust the missing exposure pathway for PBDEs? An analysis of the urban fate and human exposure to PBDEs. Environ. Sci. Technol., 39: 5121-5130.

Shoeib, M., Harner, T., Wilford, B. H., Jones, K. C., Zhu, J. (2005) Perfluorinated sulfonamides in indoor and outdoor air and indoor dust: occurrence, partitioning, and human exposure. Environ. Sci. Technol., 39: 6599-6606. 